\title{
Effects of harmonic roving on pitch discrimination
}

\section{Santurette, Sébastien; de Kérangal, Mathilde le Gal ; Joshi, Suyash Narendra}

Publication date:

2015

Document Version

Publisher's PDF, also known as Version of record

Link back to DTU Orbit

Citation (APA):

Santurette, S., de Kérangal, M. L. G., \& Joshi, S. N. (2015). Effects of harmonic roving on pitch discrimination. Poster session presented at 169th Meeting of the Acoustical Society of America, Pittsburgh, Pennsylvania, United States.

\section{General rights}

Copyright and moral rights for the publications made accessible in the public portal are retained by the authors and/or other copyright owners and it is a condition of accessing publications that users recognise and abide by the legal requirements associated with these rights.

- Users may download and print one copy of any publication from the public portal for the purpose of private study or research

- You may not further distribute the material or use it for any profit-making activity or commercial gain

- You may freely distribute the URL identifying the publication in the public portal

If you believe that this document breaches copyright please contact us providing details, and we will remove access to the work immediately and investigate your claim 


\section{(5)}

\section{Introduction}

Performance in pitch discrimination tasks is limited by variability inImitations or more central noise sources. Perceptual limitations may when introducting external noise in the physical stimulus (Lu and
washer 2008). The present study used this approach to attempt to Dosher, 2008). The present study used pins approach to atempt plex tones by estimating the amount of harmonic roving required
ple bate whether pitch perception of natural complex sounds mostly relies information. Comparing the way internal noise affects the internal representations of such information to how it affects pitch discrimination
performance may help clarify pitch coding mechanisms. As training requency discrimination tasks has been found to result in a reduction
of internal noise (Jones et al., 2013), it was also investigated whether he effect of harmolic roving varied with musical training Research questions:

- How much harmonic roving is necess
tion performance? (Experiment 1) - Does musical train
(Experiments 1-2)

- Is the effect of roving the same in low vs. high spectral regions,
where different pitch coding mechanisms and different types of in where different pitch coding mechanisms and different types of in-
ternal noise limitations may occur (Oxenham and Micheyl, 2013)?
(Experiments 2-3)

\section{Methods}

- Fundamental-frequency difference limens (FODLs) with alternative
forced-choice (AFC) task: "Choose the interval with the higher pitch

Bandpass-filtered resolved or unresolved complex tones embed-
ded in threshold-equalizing noise with roving of components on an ded in threshold-equalizing
interval-by-interval basis
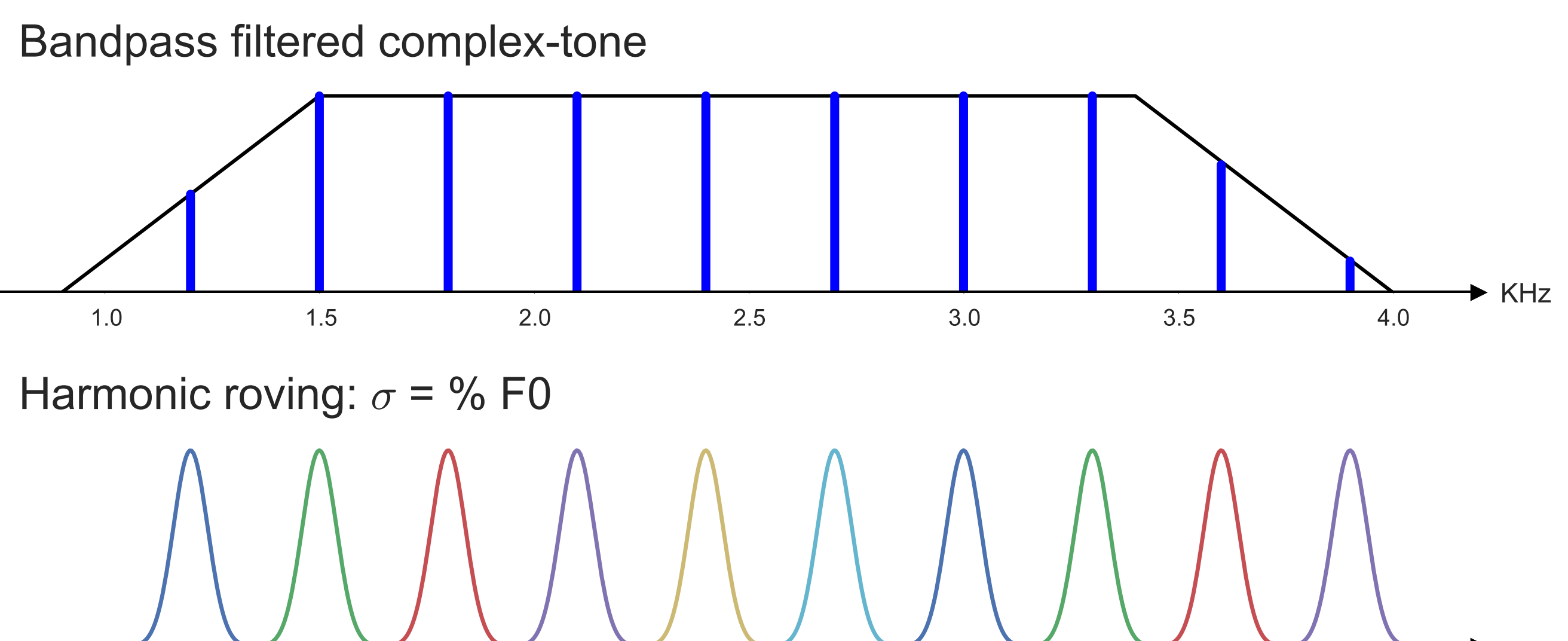

Stimulus + Masking noise (TEN)

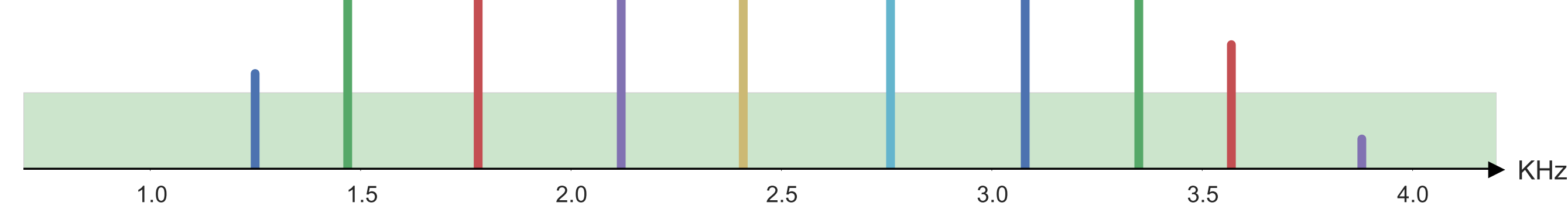

Fig.1 s simplified illustration of stimulus roving. The amount of roving is determined by the standard

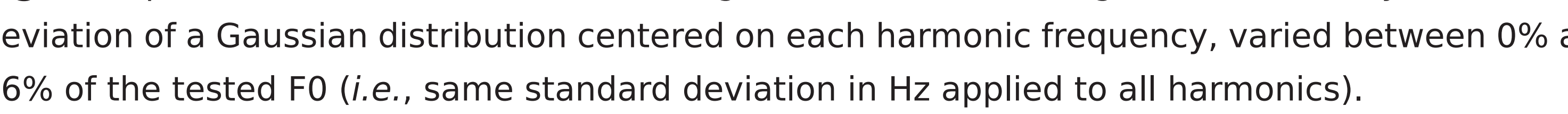
Harmonic number: 1

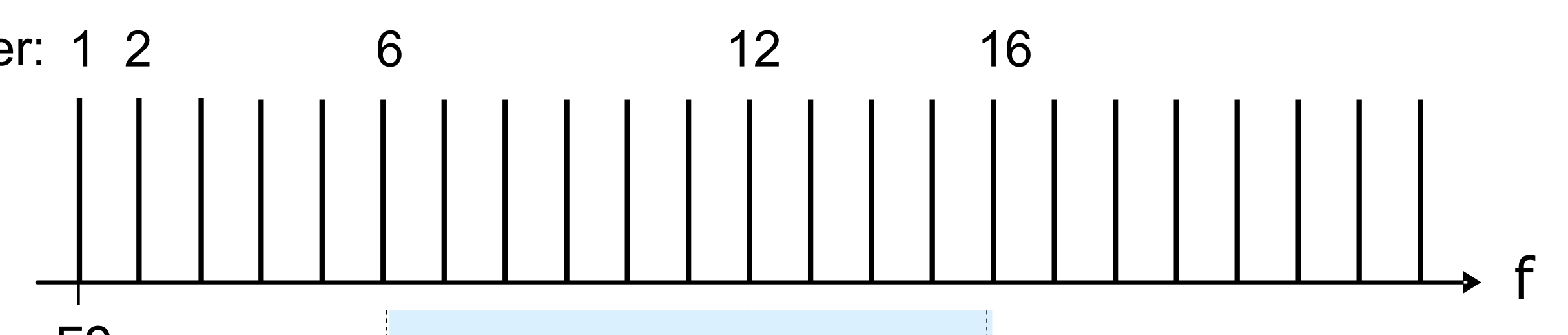

Resolvability

$\underbrace{\underbrace{}_{\text {PLCE }}}_{\text {RESOLVED }}$

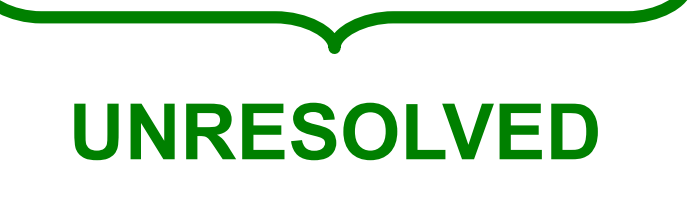

May be coded via: $\begin{gathered}\text { PLACE } \\ \text { andlor TIME }\end{gathered}$

TEMPORAL

Sébastien Santurette, Mathilde le Gal de Kérangal, Suyash N. Joshi

Hearing Systems, Department of Electrical Engineering, Technical University of Denmark

\section{1: Musicianship/Resolvability}

\section{Methods}

FODLs as a function of harmonic roving

13 normal-hearing listeners (7 musicians and 6 non-musicians)

3-AfC task, weighted up-down tracking rule (75\%)

- Complex tones bandpass

- Resolved condition: $\mathrm{F} 0=300 \mathrm{~Hz}$ (audible harmonics $5-13$ ) Results:

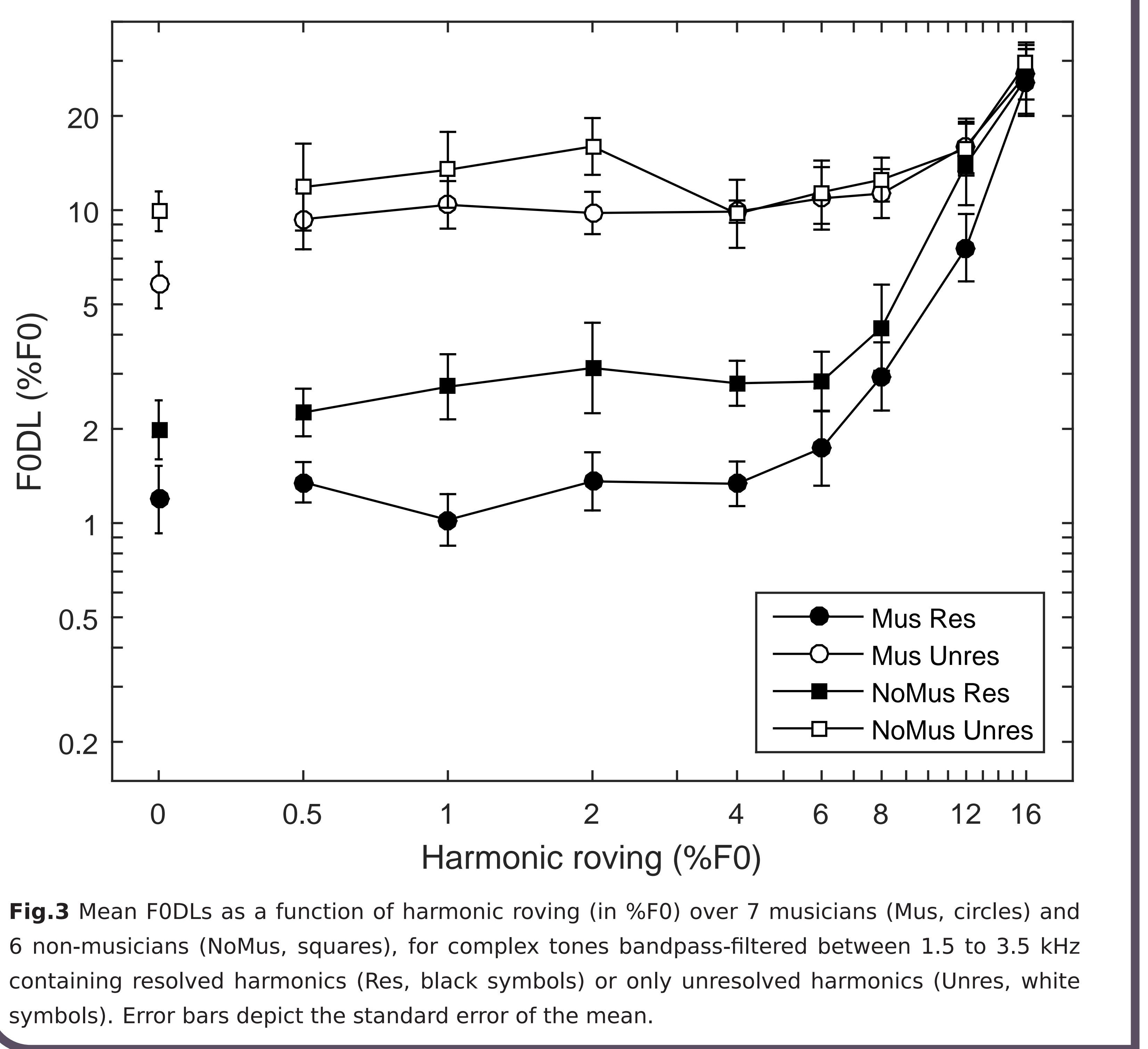

\section{Discussion}

Effect of harmonic roving on FODLs

Performance unaffected up to a certain roving amount and progres-
sively worse above (Fig. 3 )

in to ca. $6 \%$ roving

noise limits performance above this value

Influence of musical training

- Better performance with musicianship

- For both resolved and unresolved conditions (Figs.3-4)

Longer musical experience leads to even better performance (Fig.4) Consistent with an
musical training

- Musicianship does not affect the amount of roving necessary to affect

- Musicians not more robust to external stimulus degradations than
non-musicians in terms of place or periodicity cues Mugst resolved condition

Confirms that complex pitch does exist when all audible compo-
nents are above $6 \mathrm{kHz}$ (Oxenham et al., 2011)

\section{2: Spectral region/Resolvability}

\section{Methods:}

FDDLs as a function of harmonic roving

- 4 normal-hearing listeners, all $8+$ years of formal musical training 2-AfC lask, weighted up-down tracking rule $(75 \%$

- Spectral gion 1.5-3.5 kHz (LF) or $7.517 .5 \mathrm{kHz}$ (HF)

- Resolved condition: $\mathrm{F} 0=300 \mathrm{~Hz}$ (LF) or $1500 \mathrm{~Hz}$ (HF) (harm. 5-13)

- Unresolved condition: $\mathrm{F} 0=75 \mathrm{~Hz}$ (LF) or $375 \mathrm{~Hz}$ (HF) (harm. 17-55) Preliminary results:

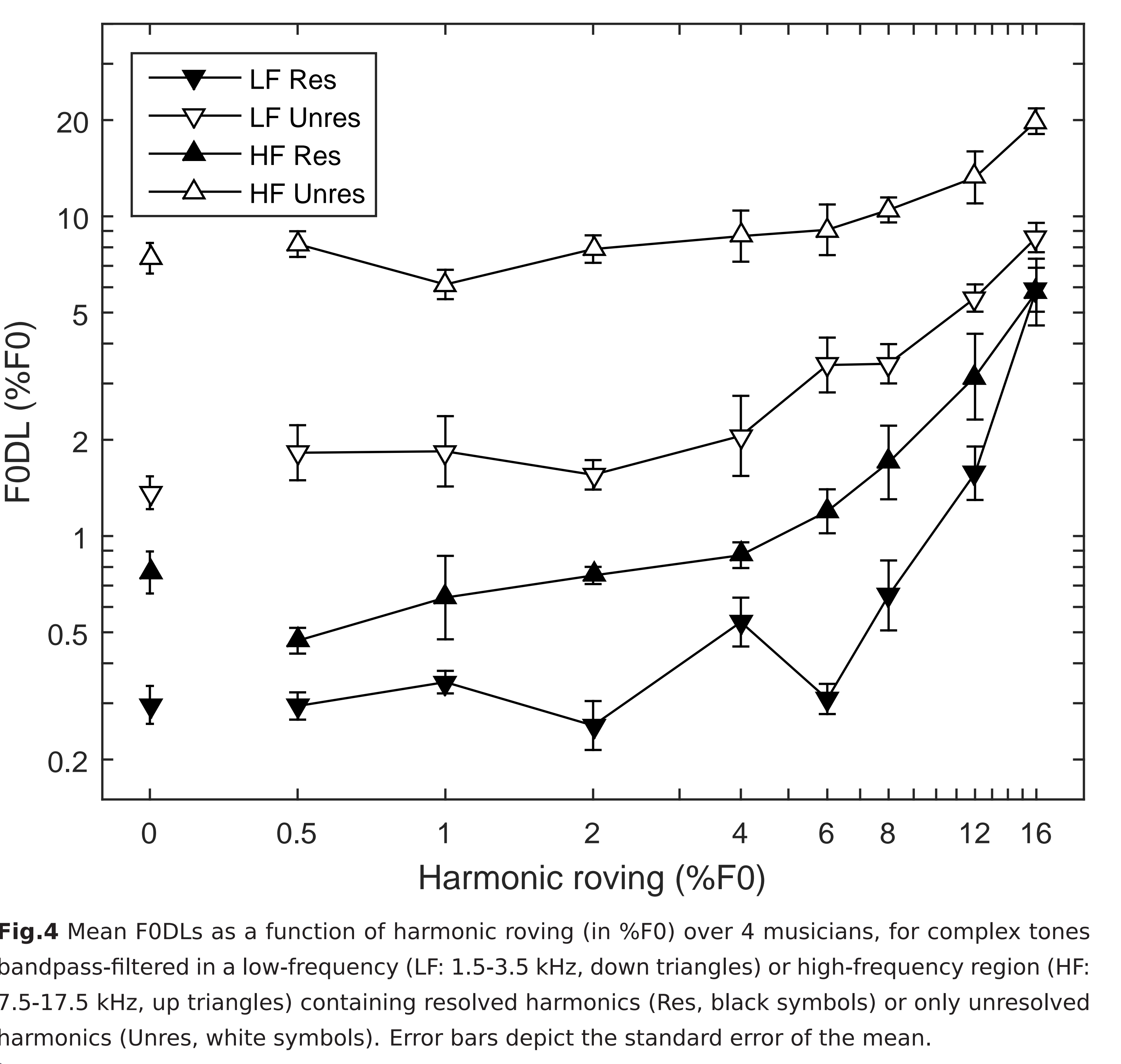

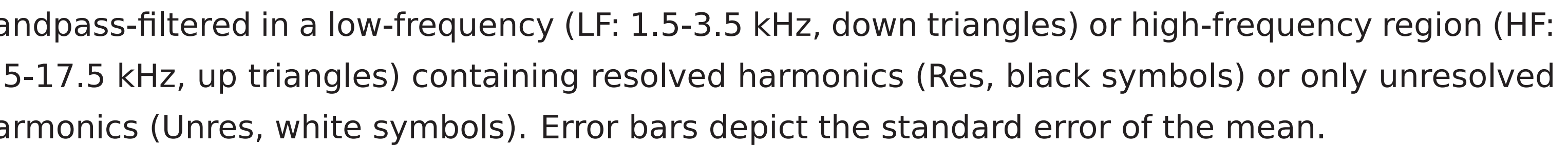

FODLs in low vs. high spectral regions

- Similar effect of roving in both spectral regions (Fig.4)

Suggest similar robustness to external noise in both regions

- Overall worse performance in HF region than in LF region (Fig.4) Resolved case: may be due to a loss of temporal fine-structure (TFS)
cues, while place cues remain available Unresolved case: due to a loss of TFS cues and/or a sluggishness of
temporal envelope coding with increasing envelope repetition rate

Comparing FODLs and FDLs for individual harmonics

- Effect of roving on FDLs dependent on spectral region (Fig.5

LF: FDLs largely independent of $F$ and increase as soon as roving
introduced

HF: Increasing FDLs with F, little roving effect up to a certain amount Suggests different mechanisms
tones at low vs. high frequencies

- FODLs not consistent with optimal integration of information across
harmonics in LF region, more so in HF region Consistent with performance being limited by different sources of
internal noise in LF (possibly central noise) and HF (possibly periphinternal noise in LF (possibly central noise) and HF (possibly periph-
eral noise) regions (Oxenham and Micheyl, 2013)

\section{3: Individual harmonics}

\section{Methods:}

Frequency difference limens (FDLs) as a function of roving:

2 normal-hearing listeners, both $8+$ years of formal musical training 2-ArC task, weighted up-down tracking rule $(75 \%)$

- Pure-tones a 1.5, 2.4, 3.3 kHz (harmonics 5, 8, 11 for LF region)

- Pure-tones at 7.5, 12.0 kHz (harmonics 5, 8 for $\mathrm{HF}$ region)

- Roving applied to nominal frequency $F$

Preliminary results:

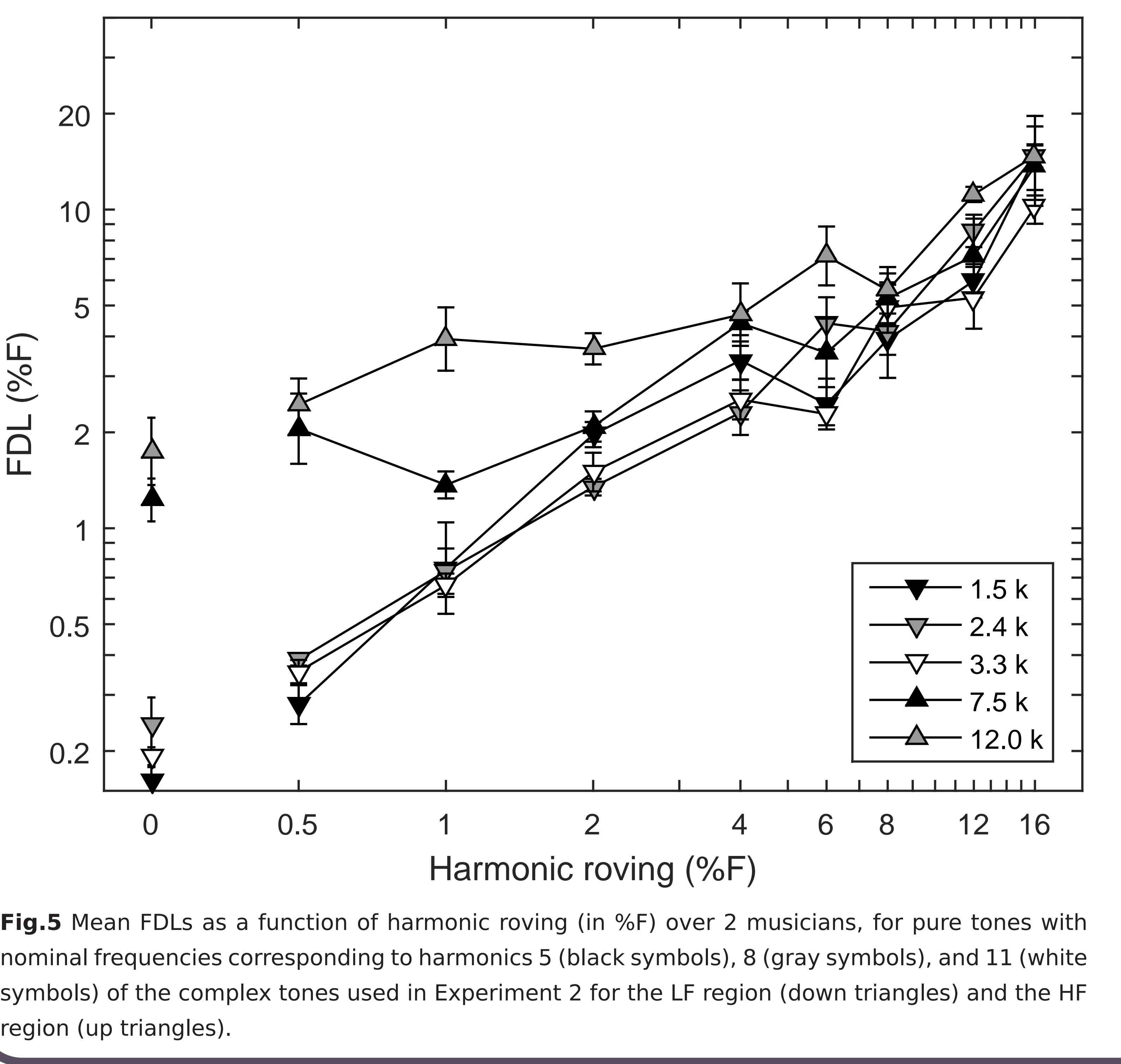

\section{Conclusions}

- The results demonstrate a systematic relationship between pitch
discrimination performance and stimulus variability that could be used to quantifif the internal noise and provide strong constraints - They are consistent with a reduction of internal noise,
spectral or temporal resolution, with musical training.

- They suggest differences in pitch mechanisms, or in the limititations
to these mechanisms, at low and high frequencies.

- Ongoing work will compare how an excitation-pattern based place model and an autcororelation based tent
ception can account for the present datt

References
lones $P$ P.

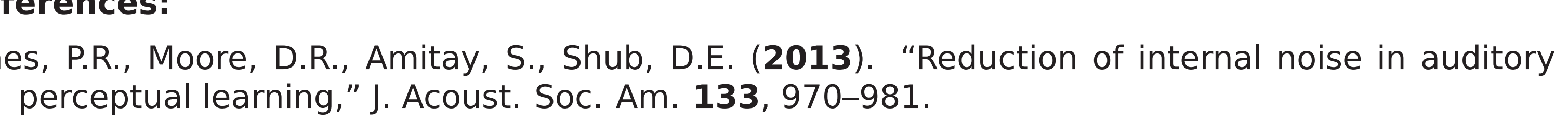

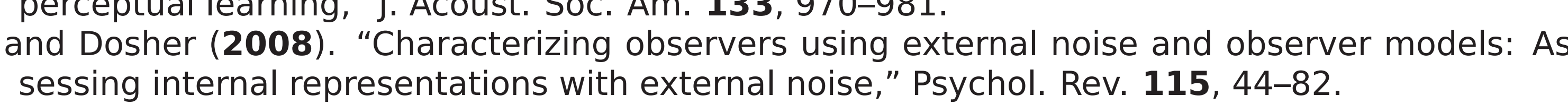

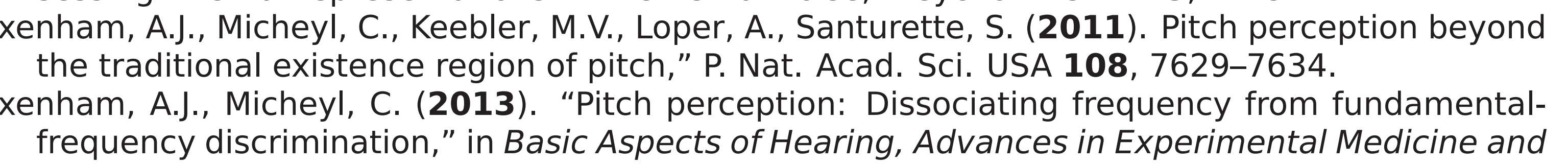

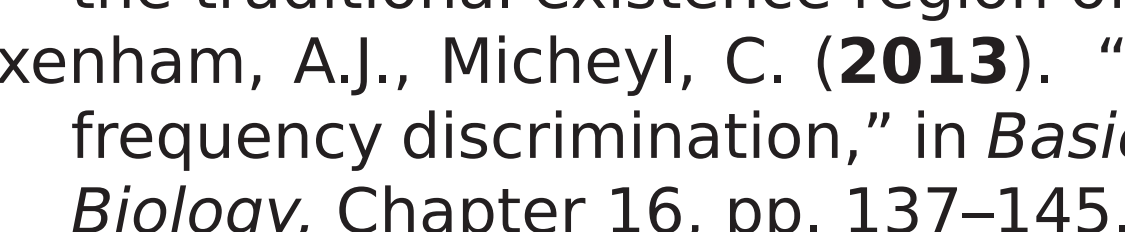

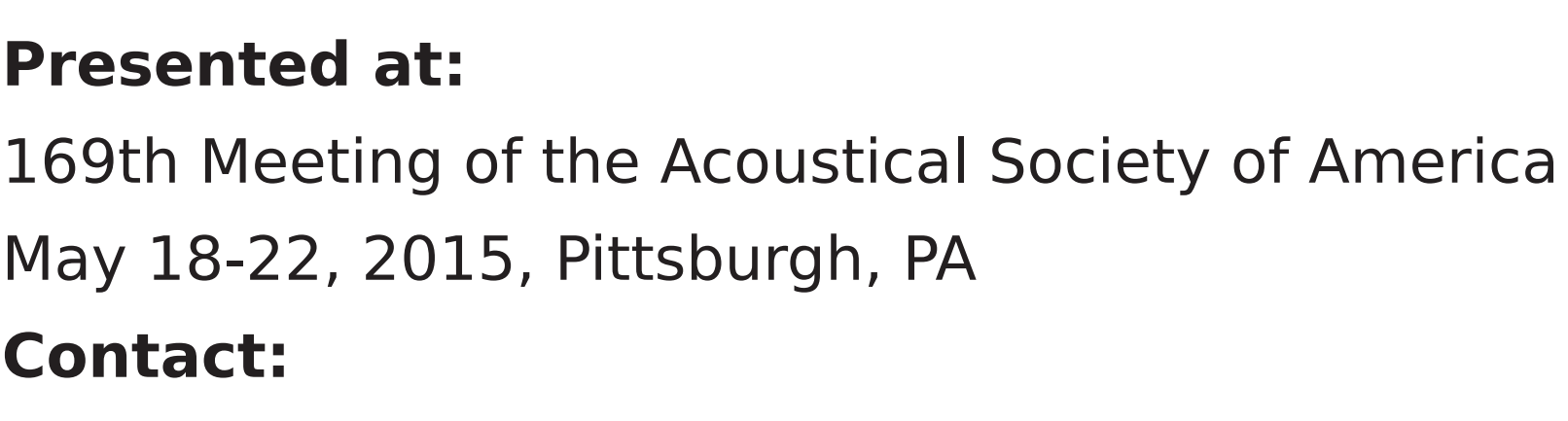

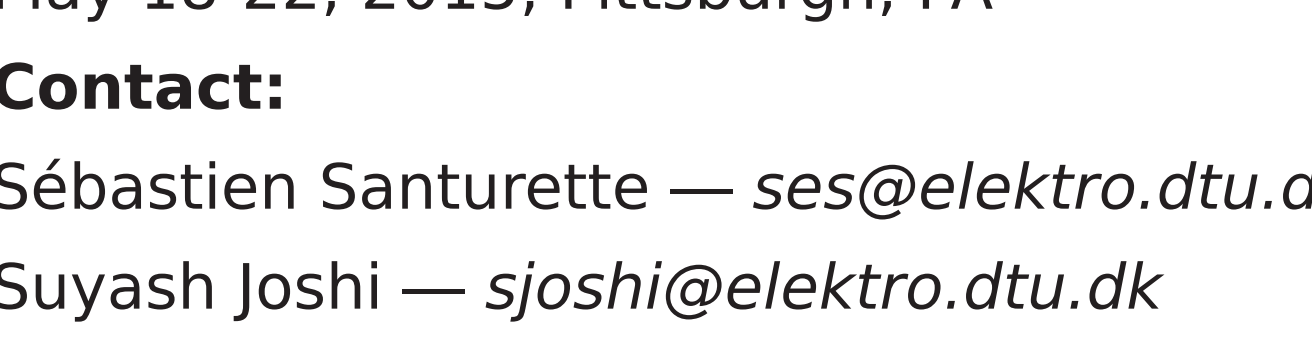

